\title{
The Flow Visualization CFD Studies of the Fuselage and Rolled-up Vortex Effects of the Chengdu J-10-like Fighter Canard
}

\author{
Sutrisno $^{1}$, Tri Agung Rochmat ${ }^{1}$, Setyawan B. W. ${ }^{1,2}$, Sigit Iswahyudi ${ }^{1,3}$, Caesar Wiratama ${ }^{1}$ \& Widia Kartika ${ }^{1}$ \\ 1 Department of Mechanical and Industrial Engineering, Faculty of Engineering, Gadjah Mada University, \\ Yogyakarta, Indonesia \\ ${ }^{2}$ Department of Mechanical Engineering, Vocation Program, Gadjah Mada University, Yogyakarta, Indonesia \\ ${ }^{3}$ Department of Mechanical Engineering, Tidar University, Magelang, Indonesia \\ Correspondence: Sutrisno, Department of Mechanical and Industrial Engineering, Faculty of Engineering, \\ Gadjah Mada University, Yogyakarta, Indonesia. E-mail: mrsutrisnougm@gmail.com
}

Received: December 13, 2017

Accepted: December 23, 2017 Online Published: January 30, 2018

doi:10.5539/mas.v12n2p148

URL: https://doi.org/10.5539/mas.v12n2p148

The research is financed by the Department of Mechanical \& Industrial Engineering, Universitas Gadjah Mada, Indonesia.

\begin{abstract}
Fighter aircrafts with high maneuverability and swiftness are due to fuselage effects, caused by canard-fuselage-main wing configuration. Even though the flows around fighters are highly complex, mostly they create rolled-up vortices capable to delay stalls and increase maximum lifts (Calderon, Wang \& Gursul, 2012; Mitchell \& Delery, 2001; Boelens, 2012; Chen, Liu, Guo \& Qu, 2015). The vortex dynamics analysis method employment is introduced, in this case we focus only on the fighter canard. It characterizes the vortex core, develops the pitching moment \& main wing total lift, and exploits the vortex centre visualization, the strength, negative surface pressure and its trajectory.

This paper explains the influence of the fighter fuselage, it generates rolled-up vortex effects, causes the flow deflected by the fighter fuselage head, strengthen the vortex centre to become vortex core. Above the aircraft head, due to the curved contour head effect, the second vortex centers are developed makes the vortex center above the head more dynamic.

Comparing with fighter without fuselage, the flow property changes, for Chengdu J-10-like model with fuselage, are concentrated at the canard leading edge, where the negative pressures are stronger, since the maximum axial velocities of the vortex centre are higher, and give more distinctive vortex breakdown locations.
\end{abstract}

Keywords: fuselage effect, rolled-up vortex, vortex breakdown, flow visualization, performance, vortex dynamic analysis, Q-criterion, J-10

\section{Introduction}

Fighter aircrafts with high maneuverability, agility and swiftness are highly demanded. During dog fighting, if a fighter pilot miss on the first shot, after maneuvering at a small-radius $180 \mathrm{o}$ turn and course reversal, the aircraft will be at a lower speed, but the design still allows the aircraft to turn within three seconds and take another shot (http://aviationweek.com/awin/sukhoi-test-pilot-explains-supermaneuver ability), with no fear of stall due to vortex breakdown and flow separation. In that moment, fighter needs significant lift increase and stall delay to postpone vortex breakdown and stall at high AoA. The strength of additional vortex lift is very reliable against the danger of stall.

The mechanism of vortex breakdown delay is largely due to the downwash created by the canard vortex in the inner part of the wing, which reduces the local effective AoA, thus suppressing flow separation and delaying the formation of the wing's leading-edge vortex (Calderon, D.E et al., 2012) (Mahdi, 2015).

\subsection{Flow Visualization, Rolled-Up Vortex and Vortex Breakdown}

Some research activities on how to control vortex behavior, rolled-up vortex transition toward vortex breakdown 
delay have been done comprehensively. Several researches in canards and LEXs fighters have been carried on. An investigation of vortex interaction in canard-forward swept wing has been conducted (Guoqing, Shuxing, \& Yong, 2010). A wing-body configuration to delay onset of vortex asymmetry have been designed (Cai, Tsai, Luo, $\&$ Liu, 2011). Three-dimensional measurements of vortex breakdown has been performed (Calderon, D.E et al., 2012). Sun et al. (Sun, Li, \& Zhang, 2013) have conducted examination on double delta fighter, Schutte et al. (Schütte, Rein, \& Höhler, 2007), have performed numerical simulation of maneuvering aircraft X31, Sahin et al. (Sahin, Yayla, Canpolat, \& Akilli, 2012) had learned flow structure over the yawed non-slender diamond wing. An integrated to UCAV stability \& control estimation X31 had been investigated (Cummings \& Schutte, 2010).

Ito et al. (Ito \& Iwashita, 2014), has studied on the aerodynamic properties of a canard-configuration, Lopez (Lopez, 1990), has examined the physical mechanisms of axisymmetric vortex breakdown. Ghoreyshi et al. (Ghoreyshi, Cummings, Ronch, \& Badcock, 2013) has learned the transonic aerodynamic load modeling of X-31 aircraft, and Ghoreyshi et al. (Ghoreyshi, Korkis-kanaan, Jirásek, Cummings, \& Lofthouse, 2016) has simulated validation of static and forced motion flow physics of a canard configured TransCruiser, Lee (2012) (Lee \& Su, 2012) had learned wingtip vortex control. Kwak et al. (Kwak, Nelson, Dame, \& Dame, 2010) had studied vortical flow control over delta wings with different sweep back angles. Sohn et al. (Sohn, Hwan Myong \& Chang, 2010) had investigated the effect of a center body on the vortex flow of a double-delta wing. Miller (Miller \& Williamson, 1997) had explored turbulent structures in the trailing vortex wake of a delta wing. In order to validate the results of CFD modeling, the experimental water tunnel results, where its accuracy was proven (Erm \& Ol, 2012), were employed.

It is unfortunate that, in the above investigations, the significance of the rolled-up vortex effect, that is the quantified measurement of the vortex developed, the tip vortex and the vortex breakdown have not been evaluated, that one could not characterize more detailed about the strength of their vortices axial speed, negative pressure and trajectory of the vortex centers including their surface pressure distribution to generate effective tangential powers.

\subsection{Turbulence, Q-Criterion Algorithm and Fuselage Effect Theory}

Some fascinating phenomena appear in the vortex dynamics mechanisms in the aerospace and aeronautical science, associated with fighters with its translational motion, which is found much alike with the vortex dynamics mechanism in the 3-D wind turbine blade field, which is with its rotational motion.

Some fighters have been modeled using several turbulence models. Q-criterion has been employed to catch the vortex centre phenomenon and the location of vortex breakdown by measuring the axial velocity along the vortex centre. The DES investigation of turbulence at a circular pier with scour hole has been carried out (Kirkil, Constantinescu, \& Ettema, 2009). Spalart-Allmaras One-Equation Turbulence (Deck, S. Duveau, P., d'Espiney \& Guillen, 2002). A DES for turbulent flows in a pipe with a snowflake fractal orifice has been learned (Nicolleau et al., 2012). It is inopportune that, the employment of the Q-criterion algorithm so far have not been combined with the footprint of the streamline for the vortex development, that complete picture of the vortex dynamics have not been constructed

Authors would like to introduce fuselage effects. The fuselage effect of canard fighters have two direct impacts, a) local canard vortex center strength (LCVCS) together with negative canard surface pressure (NCSP), with its dominance effects on low AoAs, play a significant role in the formation of canard vortex cores and negative canard surface pressure, greatly determining the strength of local canard lifts, or pitching moments of the system, and the second, b) canard vortex center trajectory, where the direction of down wash sweep is dominant on high AoA, would be very useful in generating total lift by the main wing, which is responsible to the maneuverability and the agility of the aircraft.

Direct application of fuselage effect theory is the main wings - canard interaction. There were several research which paid in depth investigations surround the main wings where canard-main wing interaction had been extensively explored and evaluated. The topology of the main vortex system and canard-wing interactions in subsonic flow had been investigated (Samimi, Davari, \& Soltani, 2013), an experimental investigations on leading-edge vortex structures for flow over non-slender delta wings had been contributed (Jin-Jun \& Wang, 2008).

It is noted that there are two canard-main wing collisions aspects one should pay attention: i) Fuselage effects on Trajectory and Fuselage effects on trajectory, whether the vortex centers is spreading, furling, widened upwards or downward give different impacts on different fuselage types, at high AoA. The second is, ii) Canard-main wing configuration effects. Canard-main wing configuration effects depend on the direction and the distance the vortex cores from canard collides with the main wing. There are 3 types arrangements, a) Canard - at a level 
above the main wing, in short distance, b) Canard - at a level almost the height of main wing, in short distance, and c) Canard - at a significant distance in front of main wing, such as Chengdu. The research studies of this matter in this field in currently in progress.

There are 2 types of canard fighter fuselage configurations, a common or straight ype fuselage configuration is the Euro-fighter (German), Rafale (France), Grippen (Sweden), and Chengdu (China), and the other type is a curved bird body-fuselage type configuration which is Sukhoi type. The focus of the current investigation is the straight fuselage configuration, namely the China-like fighter, Chengdu J-10-like model. The other type, the detail experimental and CFD modeling for the Sukhoi/curved type fuselage configuration is currently in progress.

\subsection{Detached Eddy Simulation (DES)}

In order to investigate deeply inside the vortex dynamics and turbulence using CFD simulation implementing Navier-Stokes equations, turbulence modeling was required. Some turbulence models were very well-known, namely i) DNS model solved directly at Kolmogorov micro scale without any modeling, which is costly, ii) LES model would be good for separation but perform poorly in boundary layers, and iii) RANS would so effective in boundary layers in contrary do poorly in the main stream.

Detached eddy simulation (DES) could also be chosen, it combined RANS inside the boundary layers and LES to catch the separation in the large scale turbulence field in the main stream. DES requires numerical modeling very small gridding in the boundary layer close to the wall boundary, therefore needs structured gridding with logarithmic meshes.

Some successful DES applications have been conducted. A DES based on the v2-f model have been conducted (Jee \& Shariff, 2014). DES of F-15 jet at a 65॰ angle of attack has been explored (Spalart, 2009). A comprehensive study of DES has been conducted (Travin, Shur, Strelets, \& Spalart, 1999)(Morton et al., 2004)(Mockett, 2008). DES of the flow especially behind an isolated propeller has been analyzed (Muscari \& Mascio, 2013). the current status and perspectives of DES has been reported (Squires, 2004). The current status and perspectives of DES has been reported (Morton et al., 2004).

A comparative study of RANS, DES and LES of internal torque converters flows has investigated (Liu, Liu, \& $\mathrm{Ma}, 2015)$. the prospect of using LES and DES in engineering design have been enlightened (Larsson \& Wang, 2014), Meyer et al. (Meyer, Devesa, Hickel, Hu, \& Adams, 2010) has contributed a conservative immersed interface method for LES of incompressible flows. Squires (Squires, 2010) has examined and performed a LES applications in aerodynamics. A high-order compact finite-difference scheme for LES of active flow control has been explored (Rizzetta, Visbal, \& Morgan, 2008). LES of cross-flow through a staggered tube bundle at subcritical Reynolds number has been examined deeply (Liang \& Papadakis, 2007). Hybrid LES/RANS methods for the simulation of turbulent flows has been updated (Frohlich \& Terzi, 2008). Direct numerical simulation (DNS) of a separation bubble on a rounded finite-width leading edge has been investigated (Lamballais, Silvestrini, \& Laizet, 2008).

It is unfortunate that the results, research, prediction, design on downwash, vortical flow control, turbulence structure, vortex interaction, load modeling, unsteady do not pay attention on rolled-up vortex and fuselage effects, vortex centers, quantified measurement employing Q-criterion algorithm that one could learn in detail ...

The purpose of the investigation was to simulate the fuselage effects results of the Chengdu J-10-like CFD model with and without fuselage. The study was focused on the mechanism, the interaction of the main wing, canard and the fuselage. It includes the canard vortex centre with respect to flow separation, and breakdown of the vortex centre system. In this research the analyses was strongly focused on around canards since investigations surround the main wings have been extensively conducted and reviewed. Other researches in relative location between canards-main wings, and effectiveness of canard AoA were currently in progress. In this paper, the method of vortex dynamics analysis for fighters is introduced. similar to the method for wind turbine vortex dynamics study, initiated by Sutrisno et al. (Sutrisno, Rochmat, et al., n.d.), exploit the vortex centre flow visualization.

\section{Methodology}

\subsection{Numerical Methods}

The investigated model in this study was the Chengdu J-10 fighter-like model with dimensions referring to the actual size with length: $15.49 \mathrm{~m}(50.82 \mathrm{ft})$ and wingspan: $9.75 \mathrm{~m}(31.99 \mathrm{ft})$. To reduce the computational load, some simplification was conducted for some detail drawings that were generally insignificant to the character of the flow. The model was drawn half-part (symmetrical) using CAD software and then was exported in 
3D-graphic CAD format for subsequent processing using meshing software.

Prior to numerical calculations, it was necessary to make a net on the model aircraft Chengdu J-10. Nets on the model were made by identifying aircraft parts into several blocks based on surface changes of the aircraft. The hexahedral mesh nets were structured by changing the net size starting from the wall portion as the smallest size and changing logarithmically enlarges to the outside, following Boelens (Boelens, 2012). The smallest size of the net on the wall was determined by the value of $y+\leq 1$ with the smallest cell value $0.0069 \mathrm{~mm}$. While the number of cells made was a number of 23,012,908 (23 million) net cells with a net structure that was combined between uniform and linear. The shape of the net looked like in Fig. 1a, b. The computational domain was box-shaped with half the model that would be symmetrically reflected. Determination of boundary conditions in the computational domain included the inlet portion or velocity inlet, outlet or pressure outlet, and symmetrical.

In this study, there were several variations on the attack angle (AoA) ranging from $10^{\circ}$ to $30^{\circ}$ with step $5^{\circ}$. The flow rate was set on the inlet velocity of $0.2 \mathrm{M}(76.2 \mathrm{~m} / \mathrm{s})$ flowing on the surface of the plane with $0.08 \%$ turbulence intensity. The flow analysis was based on the Navier-Stokes equation with the completion of the numerical method using the Finite Volume Method (FVM). The calculations were performed employing Fluent ANSYS R18 software.

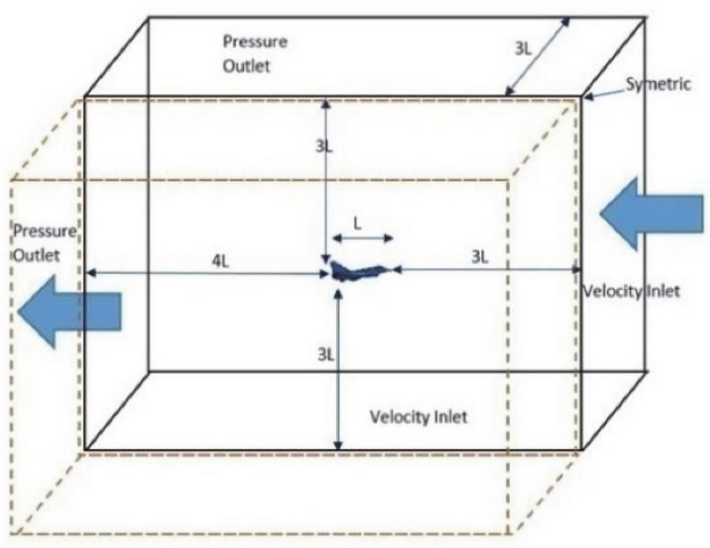

(a)

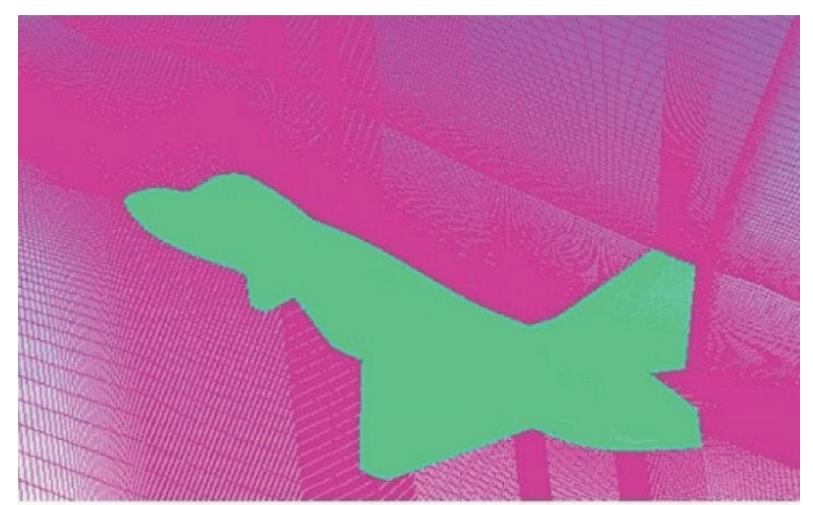

(b)

Figure 1. (a) Computational domain and (b) settings of boundary condition for half-model simulation

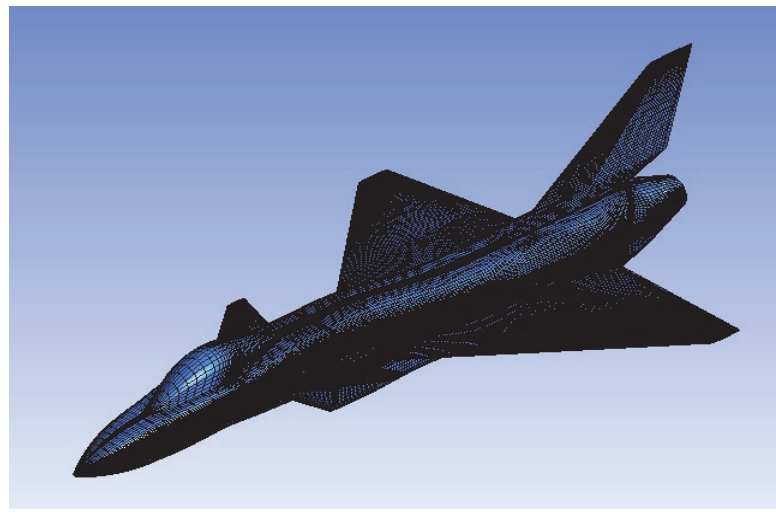

(a)

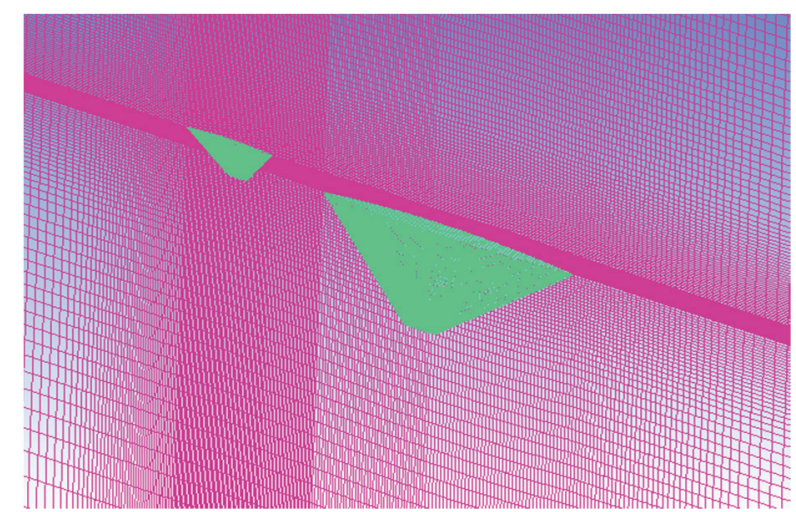

(b)

Figure 2. The pictures of a) the grid on the symmetry plane for the Chengdu J-10-like CFD model with fuselage configuration, showing computational domain for half model (symmetrical), b) computational domain for fighter model without fuselage (symmetrical)

The solution of turbulence were computed using k- $\omega$ equations and DES based S-A model. This DES method was the development of the RANS model by transferring the calculations to a more precise sub grid for the use of the LES method, whereas in the area near the wall it still used the S-A method, thereby reducing the 
computational load. To solve the equation, the coupled scheme for the settlement of pressure-velocity coupling was used, while the discretization method using 2nd order up-wind method as shown in Fig. 2a. The coupled scheme algorithm solved altogether the momentum equation and pressure-based continuity pressure equation. Full implicit coupling was obtained through the discretization of the pressure gradient on the momentum equation and the implicit discretization of the face mass flux. This solver scheme offered several advantages over the segregated pressure-based method, this method solved more quickly and efficiently especially for single-phase fluids and under steady-state flow conditions. On the other hand, Fig. $2 \mathrm{~b}$ showed computational domain for fighter model without fuselage.

\subsection{Numerical Validation}

In this study, the reference wind tunnel experiments employed for validation, as in Fig. 3, is based on the model originally used by Boelens (Boelens, 2012). The model used during the wind tunnel experiments is based on the X-31 experimental high angle-of-attack aircraft configuration, at in the DNW Low-Speed-Wind-Tunnel Braunschweig (LSWTB), DLR. Test run VN01004 has been selected from the wind tunnel data set as reference for the sectional surface pressure distributions and the aerodynamic force and moment data. This test run constitutes of an $\alpha$-sweep for angles of attack $\alpha$ ranging from $-6^{\circ}$ to $55^{\circ}$. Fig. 3 shows the validation of the lift coefficient for test run VN01004 $(\mathrm{M}=0.18$ and Rem.a.c. $=2.07 \times 106$. The wind tunnel velocity has been $60 \mathrm{~m} / \mathrm{s}$, which corresponds to a Mach number of 0.18 .

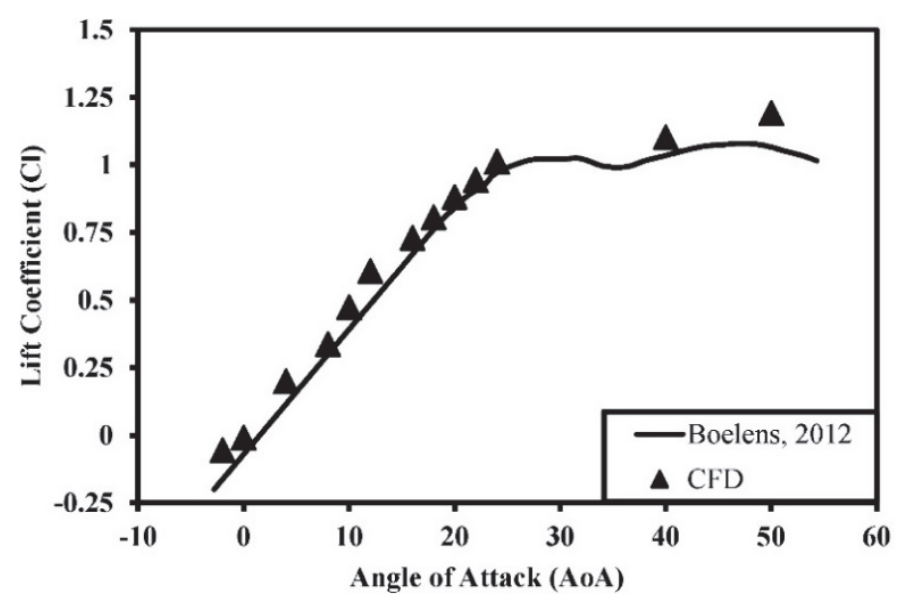

Figure 3. The lift coefficient CLfor X-31 CFD model compared against an experiment, conducted at DNW, LSWTB, DLR (Boelens, 2012) for different angle of attack $(\alpha)=0^{\circ}$ to $60^{\circ}$. It shows they match quite well

As shown in Fig. 3, the lift coefficient CL for X-31 CFD model compared against this experiment. The Navier-Stoke equation employing the k- $\omega$ equations turbulence representation with DES based S-A model, utilizing Fluent ANSYS R18 software, currently applied to X-31 CFD models, the calculation results were compared against Boelens' X-31 DNW experiment. It shows that they match quite well, as illustrated in Fig. 3.

\subsection{The Method of Vortex Dynamics Analysis}

In turbulence region, rolled-up vortex effect could generate vortices. It needs vortex dynamics analysis of 3-D flow pattern to show the interchange between rotational kinetic vortex energy and potential energy (negative pressure energy) to create lift. In order to have the whole picture of the vortex dynamics of the system, similar to (Sutrisno, Deendarlianto, Rochmat, Setyawan, \& Iswahyudi, n.d.) the authors would like to introduce the method to analyze vortex dynamics simulation. The method consists of 2 parts, the flow visualization techniques and the analysis of the results of the Q-criterion algorithm mesurement.

The first part, a) the flow visualization techniques with several steps. The first step, 1) to plot the footprint from time to time, Next step, 2) is the result of the Q-criterion algorithm, it shows the flow visualization plots of the main vortex center which may also generate the second vortex center.

The second part, $b$ ) the products of analysis to the quantified measurement of the Q-criterion algorithm due to the vortex, consists of i) the strength of the vortex center which is the axial velocity of the vortex center with respect to the local free stream velocity $\mathrm{Uo} / \mathrm{Ulocal}(\mathrm{z})$ and the pressure coefficient $\mathrm{Cp}$ of the vortex center, along the vortex centre or the measures of the pressure coefficient of the total pressure loss-center over the area under study, and ii) the measurement of the trajectory height and spanwise location of the vortex center or the center of 
the total pressure loss. It means that if the tip vortex and the vortex breakdown have not been evaluated, than one could not characterize more detailed about their surface pressure distributions to generate local lifts.

\subsection{The Fuselage Effect Theory of Canard Fighter}

In this research, something exciting is that the vortex dynamics mechanism in the aerospace and aeronautical science, associated with fighters, with its translational motion, is much like the vortex dynamics mechanism in the 3-D wind turbine blade field, which is with rotational motion.

It has been explained about the role of rolled-up vortex arises in 3-D wind turbine blades with Helicopter-Head-Like Propeller Blade Tips (Sutrisno et al., 2017) or blades with fin. In wind turbine blades, rolled-up vortex could perform laminarization effect on turbulent region which delay the stall. Furthermore, rolled-up and tip vortices arising on the swept backward wind turbine blades (Sutrisno, Deendarlianto, Rochmat, Setyawan, et al., n.d.) can occur when turbulent flows hit laminar areas, hilly terrain.

And in this paper, the authors would like to introduce a fuselage effect theory of canard fighters. It would be shown that if high-speed turbulent currents hit an aircraft head, due to the fuselage effect, a rolled-up vortex effect will occur. The vortex centers trajectory will turn in a certain direction, and vortex centers that occur could become canard vortex cores, with a particular axial vortex velocity, cause negative pressure coefficient $(-\mathrm{Cp})$. At some distance vortex core will experience breakdown as the flow stalls.

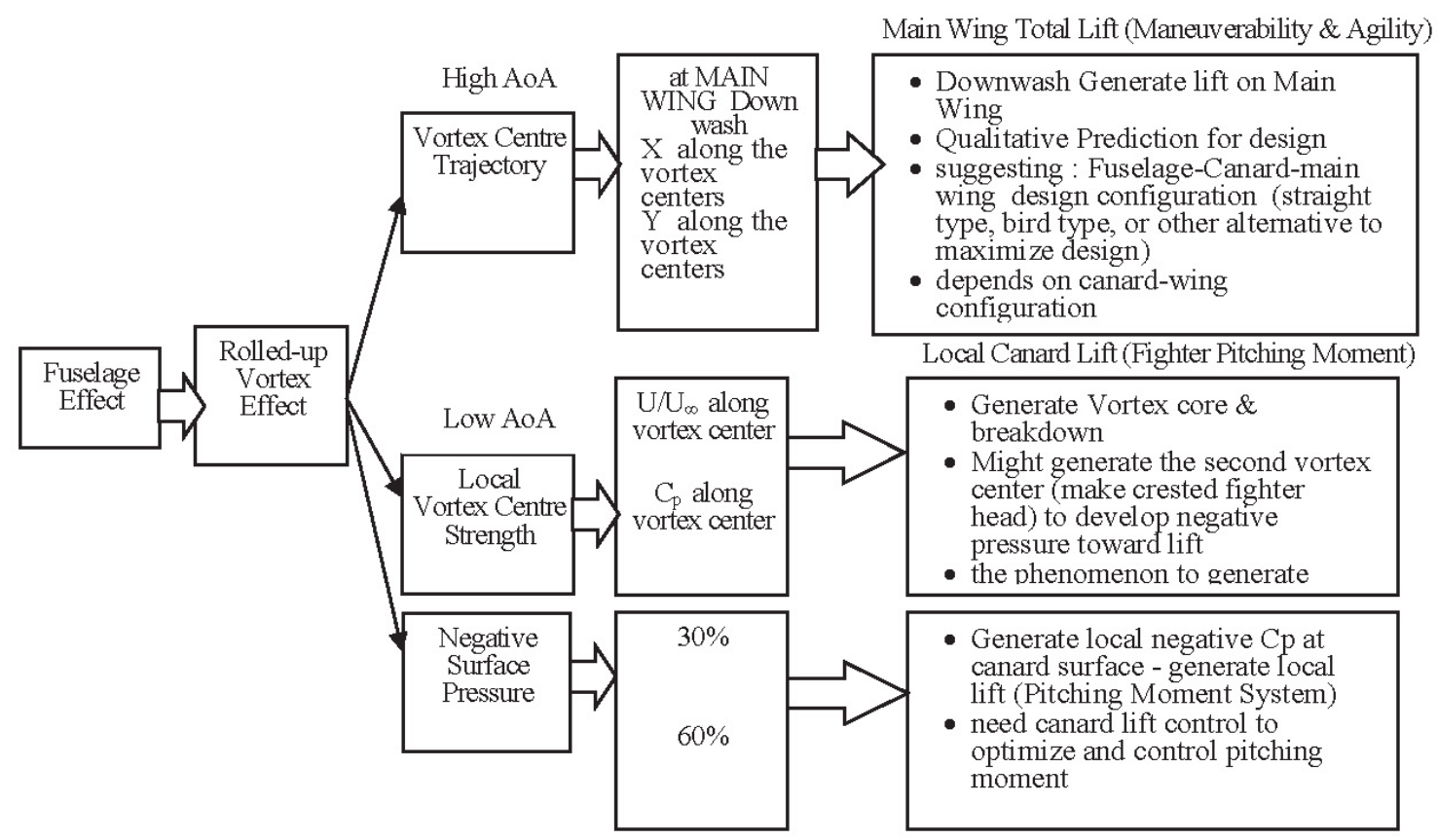

Figure 4 . The addition of fuselage on fighter system fuselage would create fuselage effect which would generate rolled-up vortex effect. And vortex center in this case would be generated

As shown in Fig. 4 that a) the local canard vortex center strength (LCVCS) and the negative canard surface pressure (NCSP), with its dominance effects on low AoAs, play a significant role in the formation of canard vortex cores and negative canard surface pressure, greatly determining the strength of the local canard lifts, or the pitching moments of the system. While b) the canard vortex center trajectory, where the direction of down wash sweep is dominant on high AoA, would be very useful in generating the total lift by the main wing, which is responsible to the maneuverability and the agility of the aircraft. Thus, it is clear here that the fuselage-canard-main wing design configuration (straight type, bird type, or other alternatives) plays strong roles in maximizing fighter design. In section 4, part 2, the continuation of further discussion of the fuselage effect theory would be concluded.

\section{Simulation Results}

\subsection{CFD Simulation \& Canard Vortex Centers of Chengdu J-10 with Fuselage}

The vortex structures of the canard are displayed in Fig. 5 for $\alpha=10^{\circ}, 15^{\circ}, 20^{\circ}, 25^{\circ}$ and $30^{\circ}$ using the $\mathrm{Q}=2.5 \times$ 
$105 \mathrm{~s}^{-2}$. It can be seen as well that the Chengdu model vortex centre with fuselage shows canard vortex breakdown at $(\alpha)=15^{\circ}$ to $25^{\circ}$. And at $\alpha \leq 10^{\circ}, \alpha \geq 30^{\circ}$ there is no vortex breakdown above the canard. In Fig. $5 \mathrm{~b}$, $\mathrm{c}$ and $\mathrm{d}$ one could observe that the canard vortex centre leading to the appearance of vortex breakdown location.
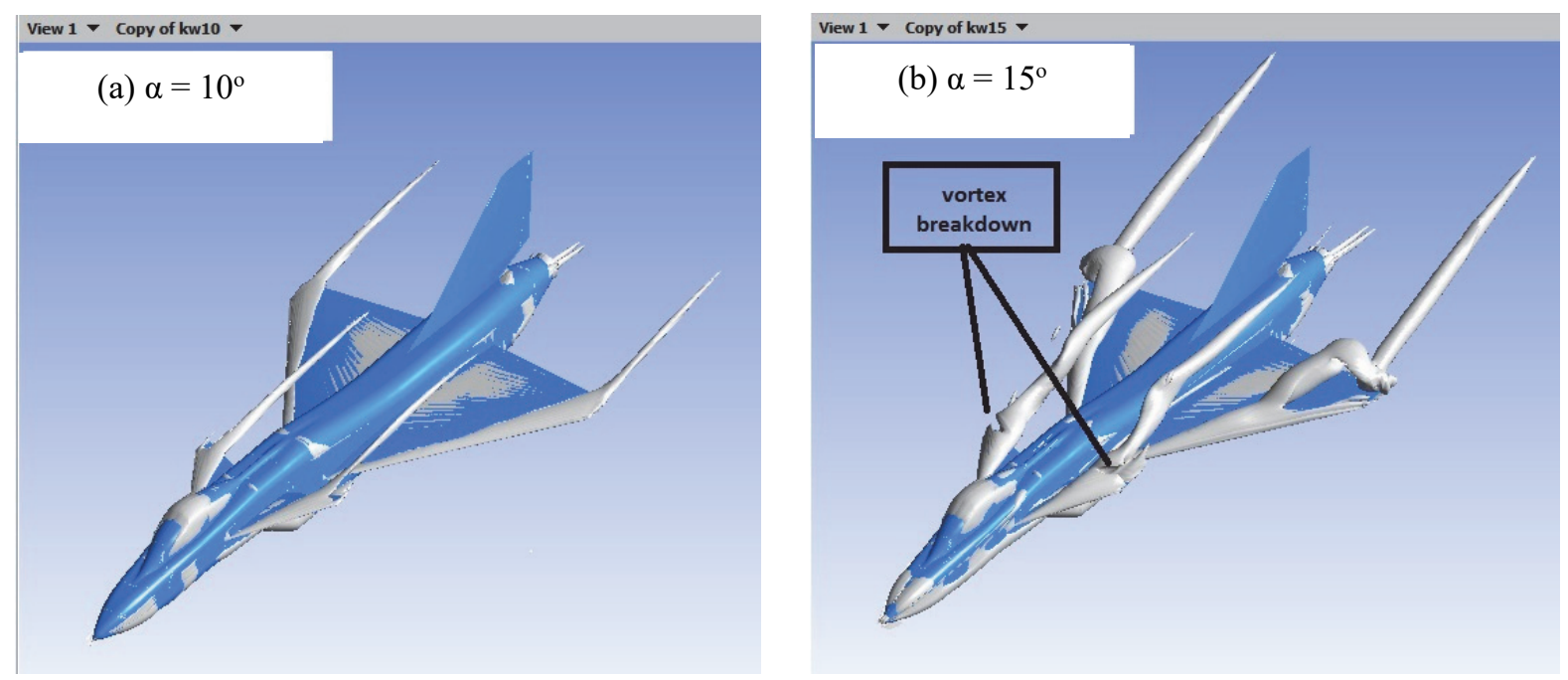

(c) $\alpha=20^{\circ}$
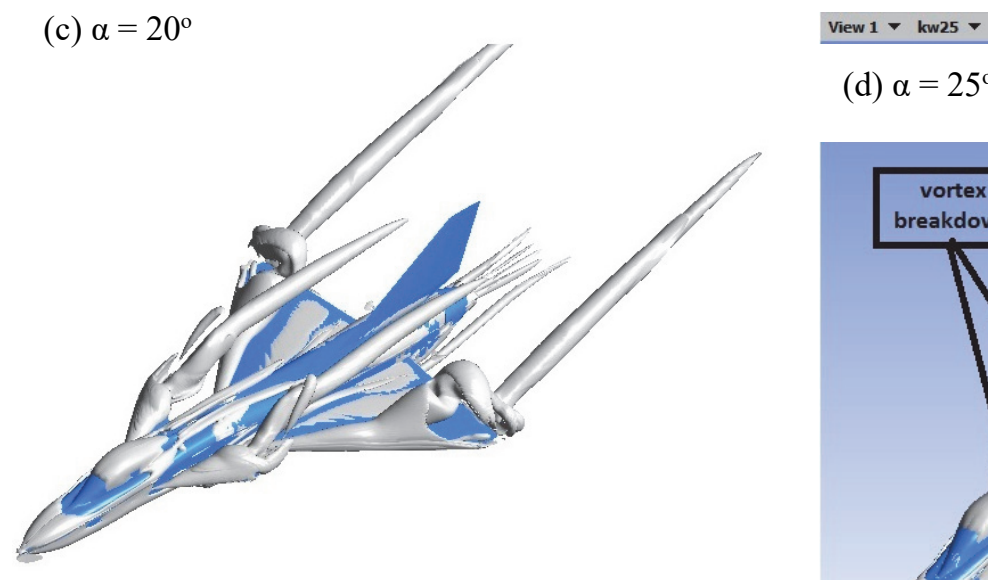

(d) $\alpha=25^{\circ}$
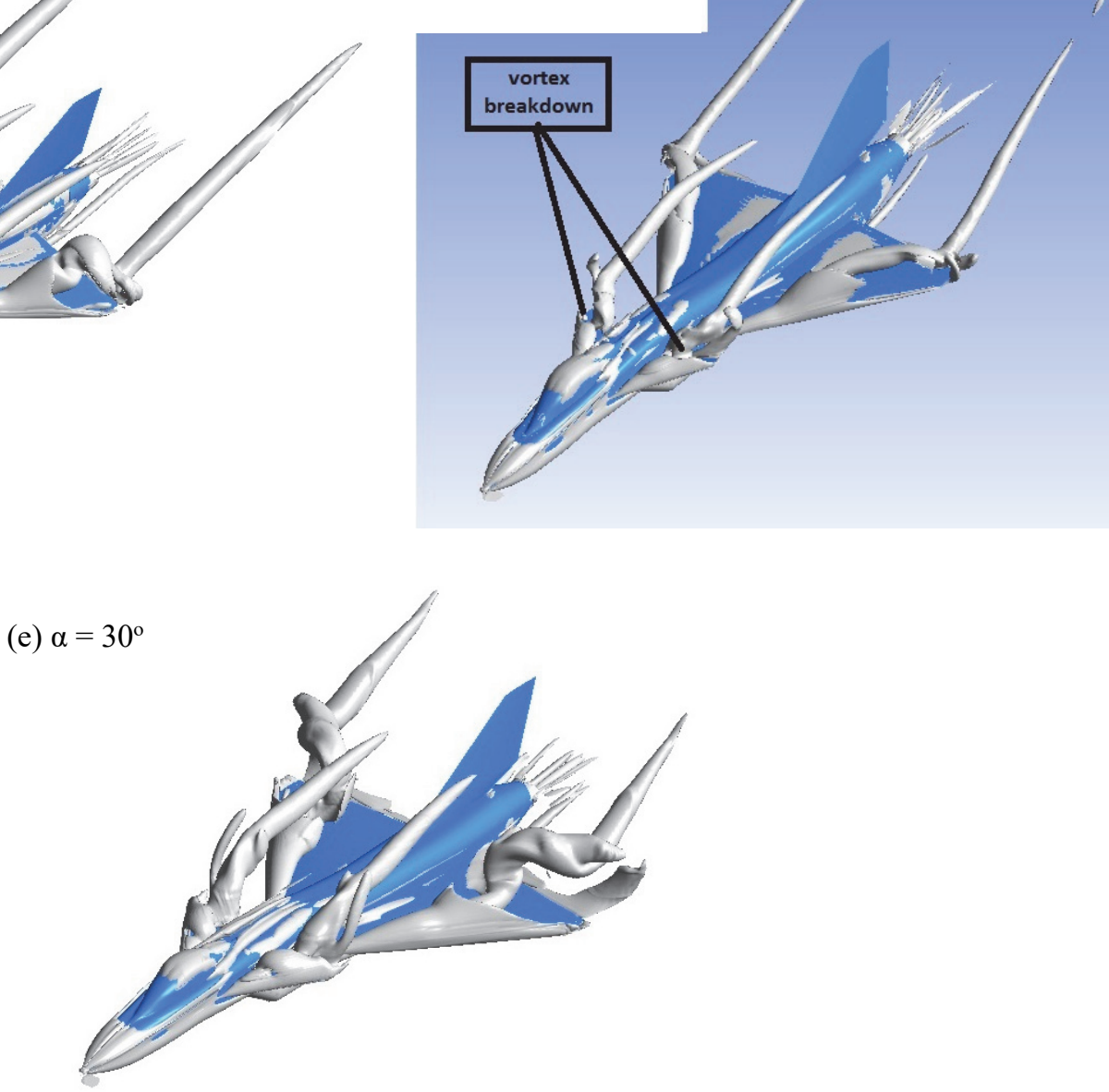

Figure 5. Flow visualization of vortex centre showing vortex break down.at angle of attack $(\alpha)=10^{\circ}, 15^{\circ}, 20^{\circ}$, $25^{\circ}$ and $30^{\circ}$ 


\subsection{Quantified Measurement Analysis of Q-criterion Algorithm of Chengdu J-10 with Fuselage}

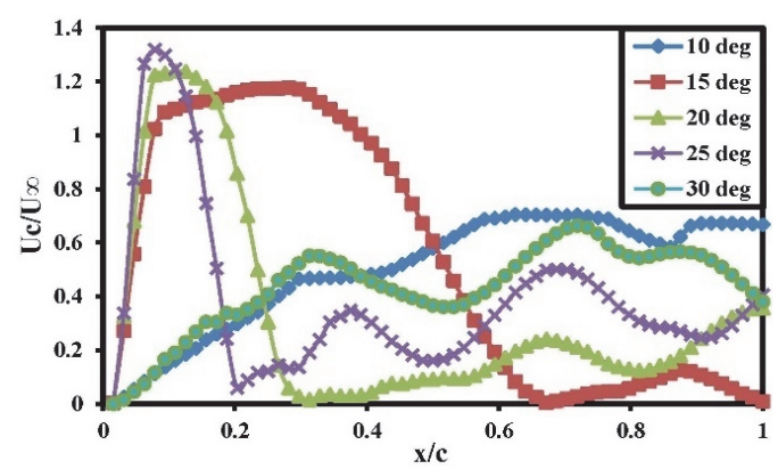

(a)

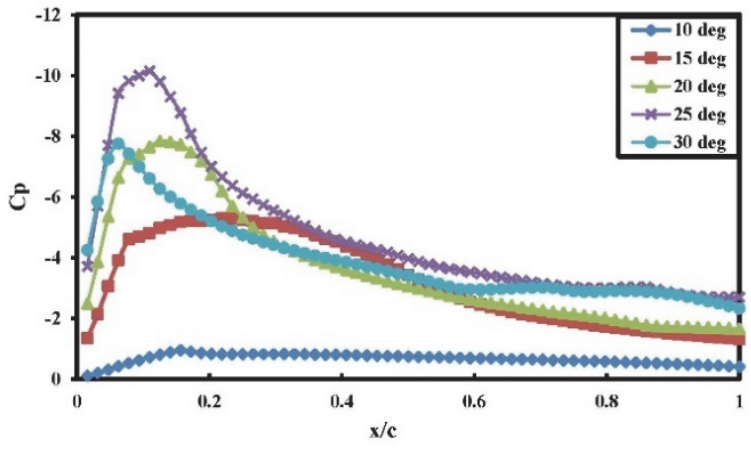

(b)

Figure 6. Plots show a) the Velocity ratio variation $U c / U \infty(\alpha)=($ Axial canard vortex centre velocity with respect

to free stream velocity) along the canard vortex centre, showing the "Vortex breakdown location", and b) pressure coefficient variation $\mathrm{Cp}(\alpha)$ along the canard vortex centre at angle of attack $(\alpha)=10^{\circ}, 15^{\circ}, 20^{\circ}, 25^{\circ}$ and $30^{\circ}$

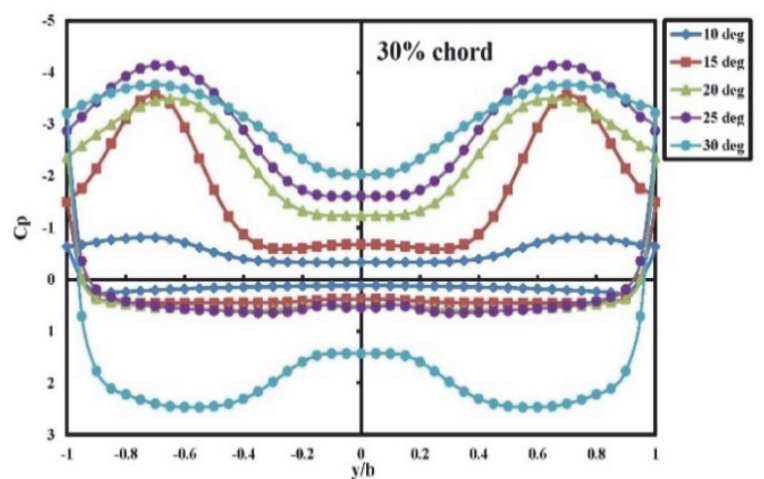

(a)

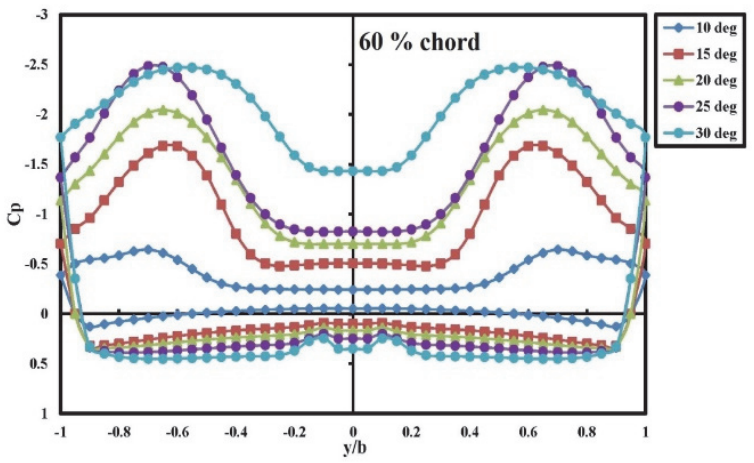

(b)

Figure 7. Curves display a) surface pressure distribution at $30 \%$ canard root chord, and b) at $60 \%$ canard root chord for different angle of attack $(\alpha)=10^{\circ}, 15^{\circ}, 20^{\circ}, 25^{\circ}$ and $30^{\circ}$

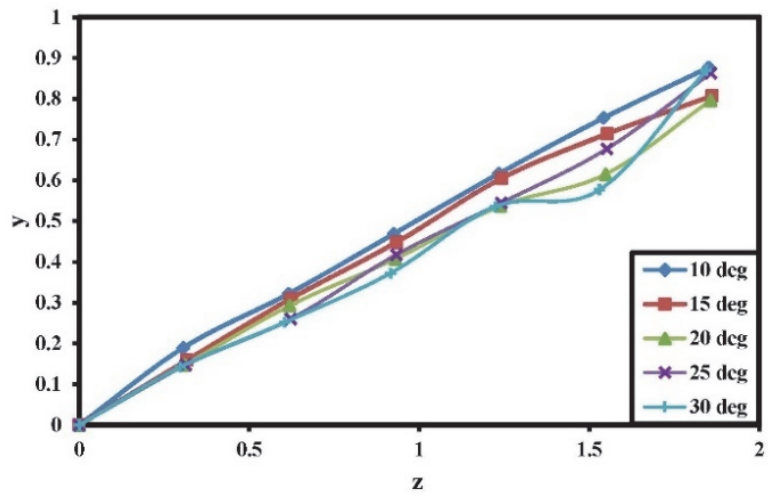

(a)

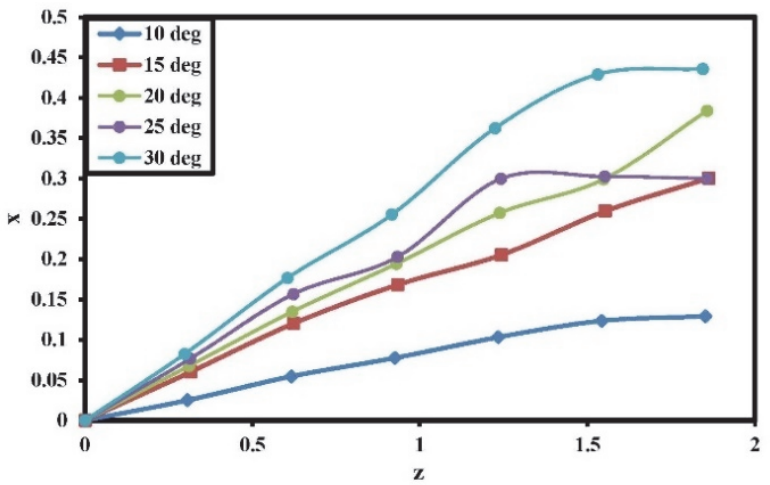

(b)

Figure 8 . The plots illustrate a) the height of vortex centre, b) spanwise location along the length of the canard vortex centre for angle of attack $(\alpha)=10^{\circ}, 15^{\circ}, 20^{\circ}, 25^{\circ}$ and $30^{\circ}$

Fig. 6a illustrates the velocity ratio variation $\mathrm{Uc} / \mathrm{U} \infty(\alpha)$, axial canard vortex centre velocity with respect to free stream velocity, along the canard vortex centre, also showing the "vortex breakdown location". It shows also that 
at $(\alpha)=10^{\circ}$ and $30^{\circ}$ the flows are not capable to generate vortex core as $\mathrm{Uc} / \mathrm{U} \infty(\alpha)<1.0$. Fig. $6 \mathrm{~b}$ demonstrates pressure coefficient variation $\mathrm{Cp}(\alpha)$ along the canard vortex centre at angle of attack $(\alpha)=10^{\circ}, 15^{\circ}, 20^{\circ}, 25^{\circ}$ and $30^{\circ}$.

The curves on Fig. 7a display a) negative surface pressure distribution at $30 \%$ canard root chord, and on Fig. $7 \mathrm{~b}$ b) at $60 \%$ canard root chord for different angle of attack $(\alpha)=10^{\circ}, 15^{\circ}, 20^{\circ}, 25^{\circ}$ and $30^{\circ}$. The plots at Fig. 8a illustrate a) the height of vortex centre, and at Fig. $8 b$ illustrate b) the spanwise location along the length of the canard vortex centre for angle of attack $(\alpha)=10^{\circ}, 15^{\circ}, 20^{\circ}, 25^{\circ}$ and $30^{\circ}$.

\subsection{CFD Simulation and Canard Vortex Centre of a Fighter without Fuselage}
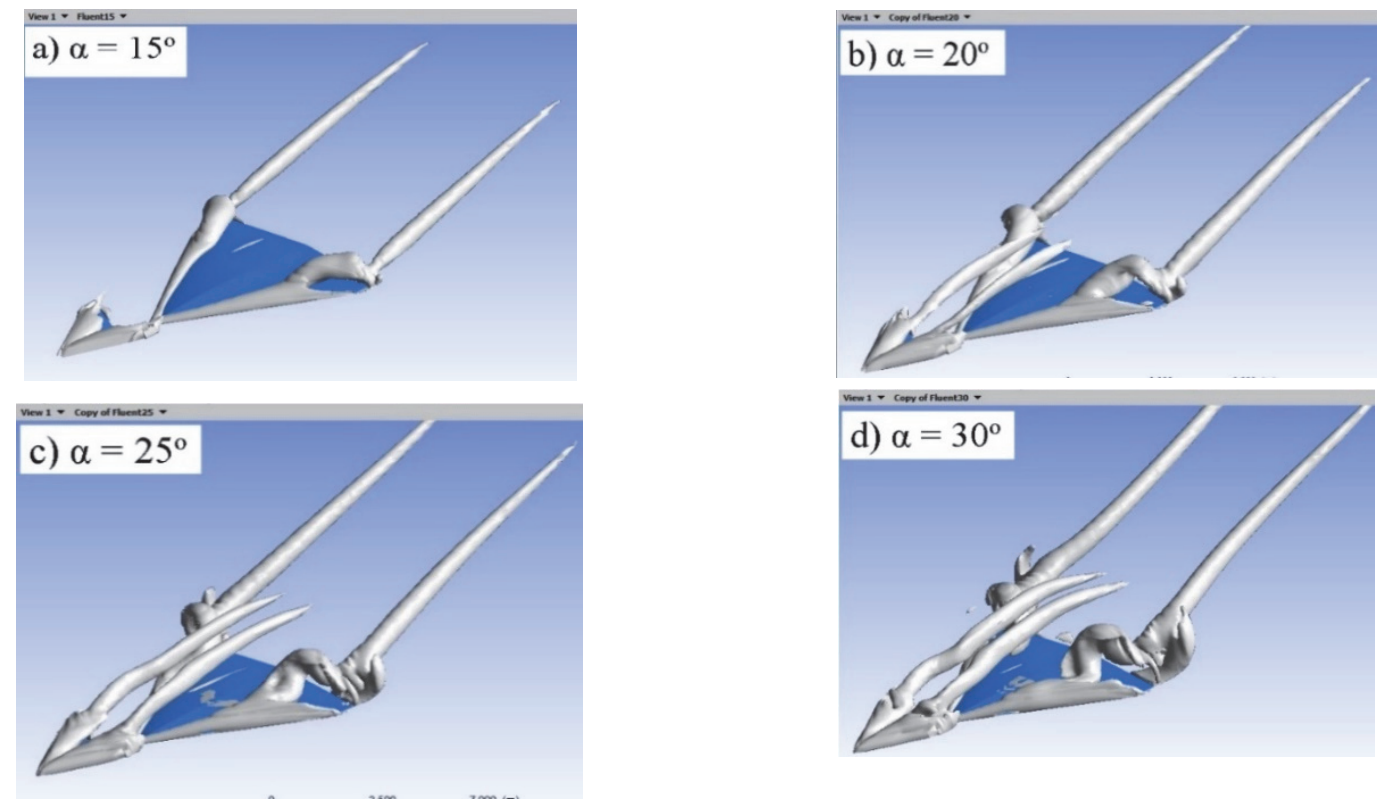

Figure 9. The plots for angle of attack $(\alpha)=15^{\circ}, 20^{\circ}, 25^{\circ}$ and $30^{\circ}$

Fig. 7a presents surface pressure distribution at $30 \%$ canard root chord, and Fig. $7 \mathrm{~b}$ at $60 \%$ canard root chord for different angle of attack $(\alpha)=5^{\circ}, 10^{\circ}, 15^{\circ}, 20^{\circ}, 25^{\circ}$ and $30^{\circ}$. The negative pressure coefficients above the canard are remarkably high at both places.

\subsection{Quantified Measurement Analysis of Q-criterion Algorithm of a Fighter without Fuselage}

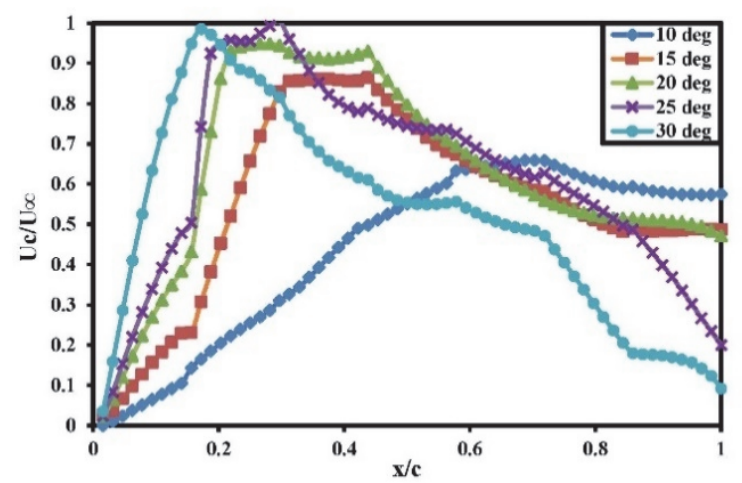

(a)

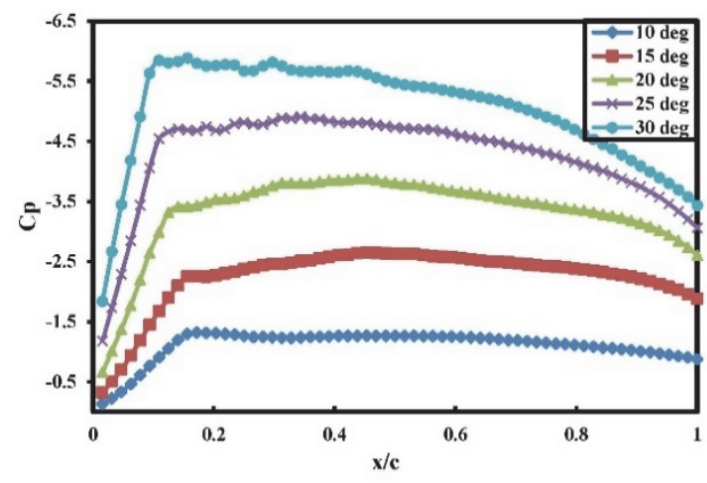

(b)

Figure 10. The curves illustrate a) the velocity ratio variation $U c / U \infty(\alpha)=($ Axial canard vortex centre velocity with respect to free stream velocity) along the canard vortex centre, showing the "Vortex breakdown location", and b) pressure coefficient variation $\mathrm{Cp}(\alpha)$ along the centre at angle of attack $(\alpha)=10^{\circ}, 15^{\circ}, 20^{\circ}, 25^{\circ}$ and $30^{\circ}$ 


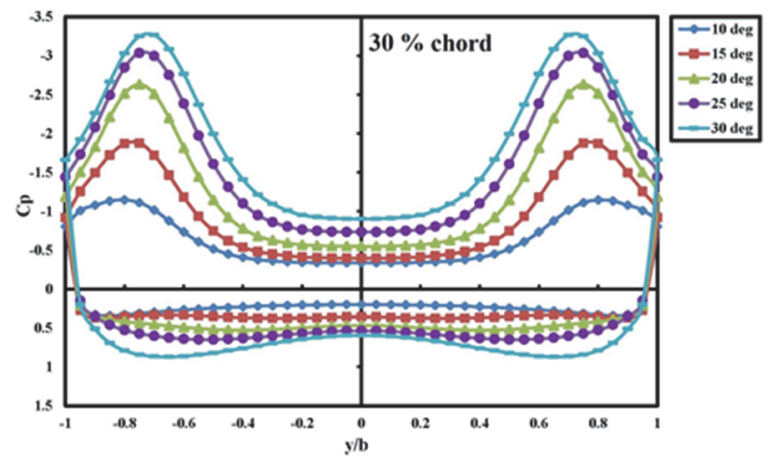

(a)

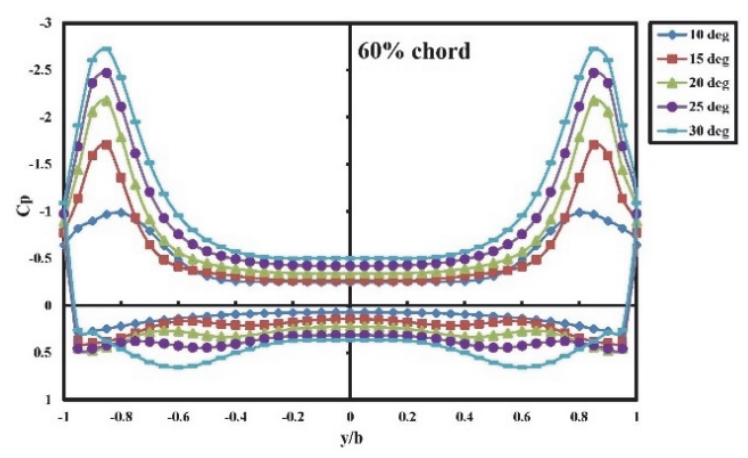

(b)

Figure 11. The plots show a) surface pressure distribution at $30 \%$ canard root chord, and b) at $60 \%$ canard root chord for different angle of attack $(\alpha)=10^{\circ}, 15^{\circ}, 20^{\circ}, 25^{\circ}$ and $30^{\circ}$

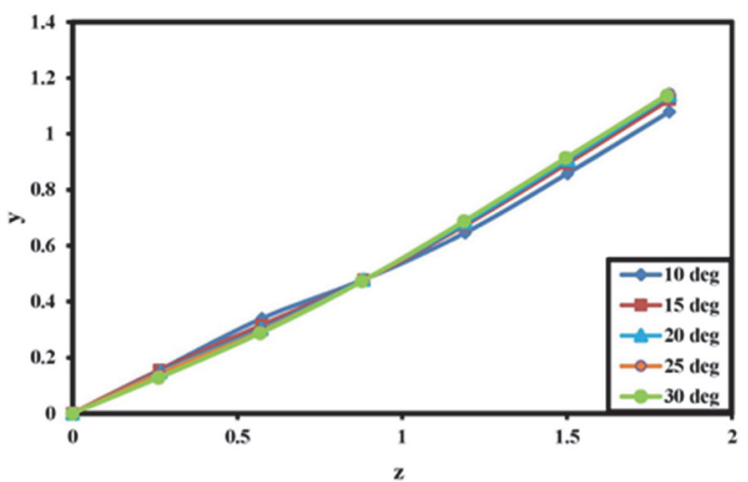

(a)

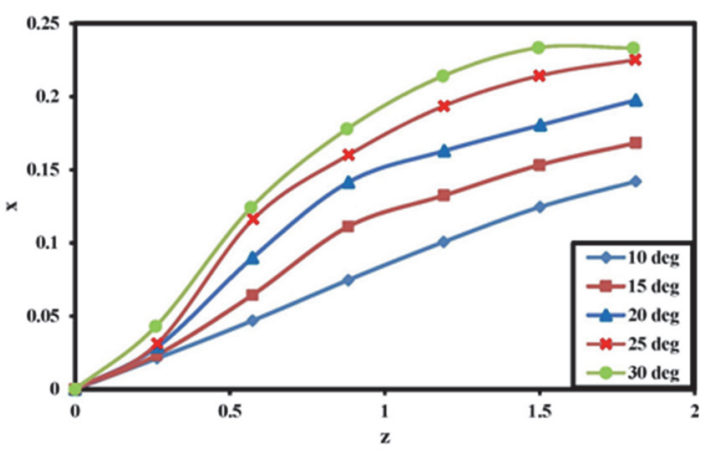

(b)

Figure 12. The curves illustrate a) the height of vortex centre, b) Spanwise location along the length of the canard vortex centre for different angle of attack $(\alpha)=10^{\circ}, 15^{\circ}, 20^{\circ}, 25^{\circ}$ and $30^{\circ}$

The vortex centre structures of the fighter without fuselage at angle of attack $(\alpha)=15^{\circ}, 20^{\circ}, 25^{\circ}, 30^{\circ}$ are demonstrated in Fig. 9, using the $\mathrm{Q}=2.5 \times 105 \mathrm{~s}^{-2}$. It can be seen as well that for the fighter without fuselage that there is no vortex core leading to vortex breakdown above the canard as $\mathrm{Uc} / \mathrm{U} \infty(\alpha)<1.0$ as seen in Fig. 10 .

Fig. 10a illustrates the velocity ratio variation, $\mathrm{Uc} / \mathrm{U} \infty(\alpha)$, which is the axial canard vortex centre velocity with respect to the free stream velocity for a fighter without fuselage, along the canard vortex centre, at $(\alpha)=10^{\circ}, 15^{\circ}$, $20^{\circ}, 25^{\circ}$ and $30^{\circ}$. One could observe that the fighter without fuselage here, the rolled-up vortex flows are not capable to produce vortex core since $\mathrm{Uc} / \mathrm{U} \infty(\alpha)<1.0$. The pressure increase, Fig. $10 \mathrm{~b}$, are not significant, and almost uniform along the vortex centre.

Fig. 11 illustrates a) surface pressure distribution for a fighter without fuselage, at $30 \%$ canard root chord, and b) at $60 \%$ canard root chord for different angle of attack $(\alpha)=10^{\circ}, 15^{\circ}, 20^{\circ}, 25^{\circ}$ and $30^{\circ}$. Fig. 12 illustrates a) the height of vortex centre, as shown at Fig. 12a, and b) Fig. 12b displays span wise location along the length of the canard vortex centre. Notice the curve of vortex center trajectory when there is no vortex core there.

\section{Discussion}

\subsection{Measured Strength, Negative Surface Pressure and Trajectory}

Table 1 show that a) surface pressure distribution at 30\% canard root chord, and b) at $60 \%$ canard root chord for different angle of attack $(\alpha)$ derived from Fig. 7a) and b) for Chengdu J-10-like CFD model with fuselage is found higher than that without fuselage. It means also that the canard coefficient of lift, for Chengdu J-10 like CFD model with fuselage is greater than that without fuselage. Then, with fuselage, due to fuselage effect, the pitching moment caused by canard is much stronger.

Table 2 shows that the velocity ratio variation $U c / U \infty(\alpha)$, or axial canard vortex centre velocity with respect to free stream velocity along the canard vortex centre, for Chengdu J-10 like CFD model with fuselage is bigger than that without fuselage. The "vortex breakdown location" for Chengdu J-10 like CFD model with fuselage, 
derived from Fig. 6a, is farther than that without fuselage derived from Fig. 10a. And the pressure coefficient variation $\mathrm{Cp}(\alpha)$ along the canard vortex centre at angle of attack $(\alpha)$, for Chengdu J-10-like CFD model with fuselage, derived from Fig. $6 \mathrm{~b}$, is higher than that without fuselage derived from Fig. 10b.

Table 2. Presenting a) Surface pressure distribution at 30\% canard root chord, and b) at $60 \%$ canard root chord for different angle of attack $(\alpha)$ at the surface of i) the canard of Chengdu J-10-like CFD model, extracted from Fig. 7a and $b$ with fuselage, ii) the canard of fighter without fuselage, extracted from Fig. 11a and b. Both are functions of $y / b$

\begin{tabular}{llllllll}
\hline & $\begin{array}{l}\text { The extreme upper } \\
\text { surface pressure coeff }\end{array}$ & $\begin{array}{l}(\alpha)= \\
0^{\circ}\end{array}$ & $\begin{array}{l}(\alpha)= \\
0^{\circ}\end{array}$ & $\begin{array}{l}(\alpha)= \\
15^{\circ}\end{array}$ & $\begin{array}{l}(\alpha)= \\
20^{\circ}\end{array}$ & $\begin{array}{l}(\alpha)= \\
25^{\circ}\end{array}$ & $\begin{array}{l}(\alpha)= \\
30^{\circ}\end{array}$ \\
\hline $\begin{array}{l}\text { Canard surface } \\
\text { of Chengdu-like CFD model } \\
\text { with fuselage i) }\end{array}$ & $-\mathrm{Cp}(\alpha) 30 \%$ & 0.0 & 0.81 & 3.56 & 3.49 & 4.13 & 3.76 \\
\hline $\begin{array}{l}\text { Canard surface } \\
\text { of Chengdu-like CFD model }\end{array}$ & $-\mathrm{Cp}(\alpha) 60 \%$ & 0.0 & 0.64 & 1.68 & 2.04 & 2.48 & 2.47 \\
ii) without fuselage & $-\mathrm{Cp}(\alpha) 30 \%$ & 0.0 & 1.18 & 1.83 & 2.62 & 3.05 & 3.48 \\
\hline
\end{tabular}

It can be observed from Table 2 that the fuselage effect on the fighter makes the flow easier for vortex core to develop and vortex breakdown location to move farther. One could learn also that for Chengdu J-10-like CFD model with fuselage, start from $\alpha=15^{\circ}$ to $25^{\circ}$, while $\mathrm{Uc} / \mathrm{U} \infty>1.0$, the vortex core starts to develop, and finish with vortex breakdown. In the meantime, for fighter without fuselage there is no vortex core development. The flow property changes of Chengdu J-10-like CFD model with fuselage, are concentrated at the canard leading edge. In comparison with that without fuselage, at the leading edge the negative pressures are stronger and the maximum axial velocities of the vortex centre are higher. And it has more distinctive vortex breakdown locations.

Table 2. Characteristics comparison between Chengdu J-10-like CFD model for (a) (c) with and for (b) without fuselage. Canard lift coefficient CLC for different angle of attack, derived from Fig. 7a, b, the Velocity ratio variation $\mathrm{Uc} / \mathrm{U} \infty(\alpha)$ along the canard vortex centre, showing the "Vortex breakdown location" derived from Fig. $6 \mathrm{a}$ (a) with and 10a (b) without fuselage and $\mathrm{Uc} / \mathrm{U} \infty(\alpha)$ along the canard vortex centre (c), showing the "Vortex breakdown location" derived from Fig. 9a with fuselage, pressure coefficient variation, $\mathrm{Cp}(\alpha)$ along the canard vortex centre derived from Fig. $6 \mathrm{~b}$ for (a) with and $10 \mathrm{~b}$ for (b) without fuselage, $\mathrm{Cp}(\alpha)$ along the main wing vortex centre derived from Fig. $9 \mathrm{~b}$ for (c) with fuselage, are functions of xc/crc at angle of attack $(\alpha)=20^{\circ}, 25^{\circ}$, $30^{\circ}, 40^{\circ}, 50^{\circ}$ and $60^{\circ}$. VBD loc is the canard vortex breakdown location

\begin{tabular}{|c|c|c|c|c|c|c|c|c|}
\hline & & $\begin{array}{c}\text { Angle of Attack } \\
\text { (AoA) }\end{array}$ & $(\alpha)=0^{\circ}$ & $(\alpha)=10^{\circ}$ & $(\alpha)=15^{\circ}$ & $(\alpha)=20^{\circ}$ & $(\alpha)=25^{\circ}$ & $(\alpha)=30^{\circ}$ \\
\hline \multirow{4}{*}{ 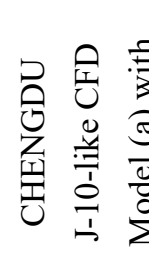 } & \multirow{4}{*}{ 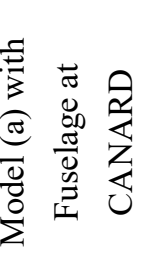 } & $\mathrm{C}_{\mathrm{LC}}($ canard $)$ & 0.0 & 0.37 & 0.55 & 0.74 & 0.87 & 0.97 \\
\hline & & $\mathrm{U}_{\mathrm{c}} / \mathrm{U}_{\infty}(\alpha)($ canard $)$ & 0 & $(0.70)$ & 1.20 & 1.27 & 1.31 & $(0.67)$ \\
\hline & & $-\mathrm{Cp}(\alpha)$ (canard) & 0.0 & 0.82 & 5.53 & 7.91 & 10.1 & 7.83 \\
\hline & & VBD loc (canard) & 0.0 & $(0.0)$ & 0.39 & 019 & 0.16 & $(0.0)$ \\
\hline \multirow{4}{*}{ 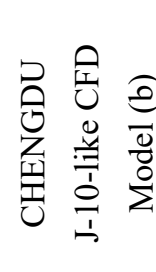 } & \multirow{4}{*}{ 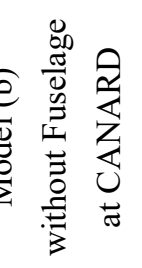 } & $\mathrm{C}_{\mathrm{LC}}($ canard $)$ & 0 & 0.3 & 0.54 & 0.73 & 0.85 & 0.95 \\
\hline & & $\mathrm{U}_{\mathrm{c}} / \mathrm{U}_{\infty}(\alpha)($ canard $)$ & 0.0 & $(0.67)$ & $(0.86)$ & $(0.93)$ & $(0.99)$ & $(0.97)$ \\
\hline & & $-\mathrm{Cp}(\alpha)$ (canard) & 0.0 & 1.21 & 2.74 & 3.93 & 4.90 & 5.82 \\
\hline & & VBD loc(canard) & 0.0 & - - & - - & - - & $(0.26)$ & $(0.16)$ \\
\hline
\end{tabular}

Table 3 shows the height of vortex centre and span wise location along the length of the canard vortex centre. It demonstrates also that the height of vortex centre derived from Fig. 8a for Chengdu J-10-like CFD model with 
fuselage is higher than that without fuselage. Due to the fuselage effect, the vortex centre of Chengdu J-10 like with fuselage exists where its height is higher than that without fuselage. It means that the height of canard vortex center with fuselage tend to be widened upwards,

The vortex centre height and its slope tend to go straight up to $\mathrm{z} / \mathrm{c} \approx 1.4$ even though the centre has been broken at $\mathrm{z} / \mathrm{c} \approx 0.16-0.39$. The vortex center height and the slope of the fighter without fuselage are lower and the vortex centers are not developed.

Table 3. The table shows, i) the height of vortex centre, ii) the slope of vortex centre height and iii) the span wise location along the canard vortex centre length derived from Fig. 8a, b (a), and from Fig. 11a, b (c) for Chengdu J-10-like CFD model with fuselage and Fig. 15a and $b(b)$ for that without fuselage

\begin{tabular}{|c|c|c|c|c|c|c|c|c|c|c|c|c|}
\hline & & AoA & $\begin{array}{l}\mathrm{xc} / \mathrm{cr} \\
\mathrm{c}=0 . \\
0\end{array}$ & $\begin{array}{l}\mathrm{xc} / \mathrm{cr} \\
\mathrm{c}=0 . \\
2\end{array}$ & $\begin{array}{l}\mathrm{xc} / \mathrm{cr} \\
\mathrm{c}=0 . \\
4\end{array}$ & $\begin{array}{l}\mathrm{xc} / \mathrm{cr} \\
\mathrm{c}=0 \\
6\end{array}$ & $\begin{array}{l}\mathrm{xc} / \mathrm{cr} \\
\mathrm{c}=0 . \\
8\end{array}$ & $\begin{array}{l}\mathrm{xc} / \mathrm{cr} \\
\mathrm{c}=1 . \\
0\end{array}$ & $\begin{array}{l}\mathrm{xc} / \mathrm{cr} \\
\mathrm{c}=1 . \\
2\end{array}$ & $\begin{array}{l}\mathrm{xc} / \mathrm{cr} \\
\mathrm{c}=1 . \\
4\end{array}$ & $\begin{array}{l}\mathrm{xc} / \mathrm{crc} \\
=1.6\end{array}$ & $\begin{array}{l}\mathrm{xc} / \mathrm{cr} \\
\mathrm{c}=1 . \\
8\end{array}$ \\
\hline \multicolumn{2}{|l|}{ Canard } & $15^{\circ}$ & 0.0 & 0.03 & 0.07 & 0.11 & 0.14 & 0.17 & 0.20 & 0.23 & 0.26 & 0.29 \\
\hline Vortex (a) & $\mathrm{h} / \mathrm{C}$ & $30^{\circ}$ & 0.0 & 0.06 & 0.12 & 0.18 & 0.24 & 0.30 & 0.36 & 0.41 & 0.43 & 0.43 \\
\hline CHENGD & Vortex & slope & 0.03 & 0.04 & 0.04 & 0.03 & 0.03 & 0.03 & 0.03 & 0.03 & 0.03 & 0.03 \\
\hline $\mathrm{U}$ & Centre & $15^{\circ}$ & & & & & & & & & & \\
\hline \multirow{3}{*}{$\begin{array}{l}\text { J-10-like } \\
\text { CFD } \\
\text { Model } \\
\text { with } \\
\text { Fuselage }\end{array}$} & Height & $\begin{array}{l}\text { slope } \\
30 \mathrm{o}\end{array}$ & 0.06 & 0.06 & 0.06 & 0.06 & 0.06 & 0.06 & 0.05 & 0.02 & 0.00 & 0.00 \\
\hline & $\mathrm{y} / \mathrm{bC}$ & $15^{\circ}$ & 0.0 & 0.09 & 0.20 & 0.30 & 0.40 & 0.48 & 0.59 & 0.67 & 0.73 & 0.78 \\
\hline & $\begin{array}{l}\text { spanwise } \\
\text { location }\end{array}$ & $30^{\circ}$ & 0.0 & 0.12 & 0.22 & 0.31 & 0.41 & 0.50 & 0.53 & 0.55 & 0.62 & 0.84 \\
\hline \multirow{10}{*}{$\begin{array}{l}\text { Canard } \\
\text { Vortex } \\
\text { (b) } \\
\text { CHENGD } \\
\text { U } \\
\text { J-10-like } \\
\text { CFD } \\
\text { Model } \\
\text { without } \\
\text { Fuselage }\end{array}$} & & $15^{\circ}$ & 0.0 & 0.02 & 0.04 & 0.07 & 0.10 & 0.12 & 0.13 & 0.15 & 0.16 & 0.17 \\
\hline & $\mathrm{h} / \mathrm{C}$ & & & & & & & & 5 & & & \\
\hline & Vortex & $30^{\circ}$ & 0.0 & 0.03 & 0.08 & 0.13 & 0.16 & 0.19 & 0.21 & 0.22 & 0.230 & 0.22 \\
\hline & Centre & & & & & & & & 5 & 5 & & 5 \\
\hline & Height & slope & 0.02 & 0.02 & 0.02 & 0.03 & 0.03 & 0.02 & 0.01 & 0.01 & 0.01 & 0.01 \\
\hline & & $15^{\circ}$ & & & & & & & 5 & 5 & & \\
\hline & & slope & 0.03 & 0.03 & 0.05 & 0.05 & 0.03 & 0.01 & 0.01 & 0.00 & 0.0 & -0.0 \\
\hline & & $30^{\circ}$ & & & & & & 5 & 0 & 5 & & 05 \\
\hline & $\mathrm{y} / \mathrm{bC}$ & $15^{\circ}$ & 0.0 & 0.12 & 0.25 & 0.37 & 0.49 & 0.61 & 0.72 & 0.83 & 0.95 & 1.05 \\
\hline & $\begin{array}{l}\text { spanwise } \\
\text { location }\end{array}$ & $30^{\circ}$ & 0.0 & 0.13 & 0.26 & 0.39 & 0.49 & 0.61 & 0.73 & 0.85 & 0.99 & 1.07 \\
\hline
\end{tabular}

\subsection{The Fuselage Effect of Canard Fighters}

The fuselage effect of canard fighters have two direct impacts, a) the local canard vortex center strength (LCVCS) together with negative canard surface pressure (NCSP), with its dominance effects on low AoAs, play a significant role in the formation of canard vortex cores and negative canard surface pressure, greatly determining the strength of local canard lifts, or pitching moments of the system. Vortex centers and cores strength $U c / U \infty(\alpha)$, $-\mathrm{Cp}$, and negative surface pressure are determined by configuration of the fuselage and canard design. Regrettably, it is not relevant to discuss this further.

The second impact is on b) the canard vortex center trajectory, where the direction of down wash sweep is dominant on high AoA, would be very useful in generating total lift of the main wing, which is responsible to the maneuverability and the agility of the aircraft. There are two aspects one should pay attention: i) the fuselage effects on trajectory and ii) the canard-main wing configuration effects.

The fuselage effects on the canard vortex core trajectory, whether the vortex centers is spreading, furling, widened upwards or downward give different impacts on different fuselage types, at high AoA. For fighters with straight fuselage type, such as Chengdu, would give spreading and widened upward effects, as seen in Fig, 8a and b. It expected, similar to what happen to Ravale, Eurofighter and Grippen. Fuselage effects would be different for Sukhoi Su-30 with birdy fuselage. It is expected to be furling and widened upward effects, which would gives much advantages, but research studies in this field in currently in progress.

Canard-main wing configuration effects depend on the direction and the distance the vortex cores from canard collides with the main wing. There are 3 types arrangements, a) Canard - at a level above the main wing, in short 
distance, b) Canard - at a level almost the height of main wing, in short distance, and c) Canard - at a significant distance in front of main wing, such as Chengdu. The research studies of this matter in this field is currently in progress.

\section{Conclusion}

Some fascinating phenomena appear in the vortex dynamics mechanisms in the aerospace and aeronautical science, associated with fighters with its translational motion, which is found much alike with the vortex dynamics mechanism in the 3-D wind turbine blade field, which is with its rotational motion.

Since the beginning of the research process, the role of rolled-up vortex has been recognized. The 3-D wind turbine blade has been introduced (Sutrisno, Prajitno, Purnomo, \& B.W. Setyawan, 2016), and then followed by the highlighting of the rolled-up vortex effect, as vortex appears on 3D wind turbine blade with helicopter head and with fin [46], when strong turbulent flow collides with fighter head creates fuselage effect which is rolled-up vortex effect [45], or strong turbulent flow collides with hills or islands also creates rolled-up vortex effect.

The method of vortex dynamics analysis is then introduced employing Q-criterion algorithm (Sutrisno, Deendarlianto, Rochmat, Setyawan, et al., n.d.). The method combines 2 parts, the employment of flow visualization techniques and the analysis of the the Q-criterion algorithm measurement result. The first part, a) the result of the Q-criterion algorithm, will show the flow visualization plots of the main vortex center which may capable to generate the second vortex center. The second, b) the analysis to the quantified measurement of the Q-criterion algorithm due to the vortex, to produce i) the strength of the vortex center which is the axial velocity of the vortex center with respect to the local free stream velocity and the negative pressure coefficient $\mathrm{Cp}$ of the vortex center, along the vortex centre, and ii) the measurement of the trajectory height and spanwise location of the vortex center.

In analyzing the fuselage effects on fighters, the authors would like to introduce the fuselage effect theory. The fuselage effect of the canard fighters have two direct impacts. The first is a) local canard vortex center strength (LCVCS) together with negative canard surface pressure (NCSP), with its dominance effects on low AoAs, play a significant role in the formation of canard vortex cores and negative canard surface pressure, greatly determining the strength of local canard lifts, or pitching moments of the system. Vortex centers and core strength $\mathrm{Uc} / \mathrm{U} \infty(\alpha),-\mathrm{p}$, negative surface pressure is determined by configuration of the fuselage and canard design. It is not relevant to discuss this further. The second, b) canard vortex center trajectory, where the direction of down wash sweep is dominant on high AoA, would be very useful in generating total lift by the main wing, which is responsible to the maneuverability and the agility of the aircraft.

There are two collisions aspects one should pay attention, i) the fuselage effects on trajectory and ii) the canard-main wing configuration effects. There are 3 types arrangements, a) Canard - at a level above the main wing, in short distance, b) Canard - at a level almost the height of main wing, in short distance, and c) Canard at a significant distance in front of main wing, such as Chengdu. The research studies of this matter in this field in currently in progress.

Comparing with model without fuselage, a) negative surface pressure distribution at $30 \%$ and b) at $60 \%$ canard root chord for model with fuselage is found higher. It means that the canard coefficient of lift is greater, the pitching moment caused by canard is much stronger with fuselage. The velocity ratio variation $\mathrm{Uc} / \mathrm{U} \infty(\alpha)$, or axial canard vortex centre velocity is bigger, the "vortex breakdown location" is farther for fighter with fuselage than that without fuselage. The pressure coefficient variation $\mathrm{Cp}(\alpha)$ along the canard vortex centre for model with fuselage is higher than that without fuselage. Then the fuselage effect makes the flow easier for vortex core to develop and vortex breakdown location to move farther. The flow property changes of Chengdu J-10-like CFD model with fuselage, are concentrated at the canard leading edge. In comparison at the leading edge for model with fuselage, the negative pressures are stronger and the maximum axial velocities of the vortex centre are higher. And it has more distinctive vortex breakdown locations.

The height of vortex centre for model with fuselage is higher than that without fuselage. The vortex centre of model with fuselage exists, where its height is higher than that without fuselage. The vortex centre height and its slope tend to go straight. The vortex center height and the slope of the fighter with fuselage are higher.

\section{Nomenclature}

$\alpha=$ angle of attacks (AoA deg)

Remac $=$ mean aerodynamic chord Reynold number

$\mathrm{y}+=$ smallest cell value 


$\begin{array}{ll}\mathrm{M} & =\text { Mach number } \\ \mathrm{CL} & =\text { lift coefficient } \\ \mathrm{Cp} & =\text { pressure coefficient } \\ \mathrm{VBD} & =\text { vortex breakdown location } \\ \mathrm{Uc} & =\text { axial canard vortex centre velocity }(\mathrm{m} / \mathrm{s}) \\ \mathrm{U} \infty & =\text { free stream velocity }(\mathrm{m} / \mathrm{s}) \\ \mathrm{h} / \mathrm{C} & =\text { vortex centre height } \\ \mathrm{y} / \mathrm{bC} & =\text { spanwise location } \\ \mathrm{bC} & =\text { canard wide } \\ \mathrm{xc} / \mathrm{crc} & =\text { centre distance with respect to canard } \\ \mathrm{crc} & =\text { canard chord at canard centre } \\ \rho & =\text { density }(\mathrm{kg} / \mathrm{m} 3) \\ \mathrm{Q} & =\mathrm{Q}-\text { criterion }(\mathrm{s}-2)\end{array}$

\section{Acknowledgement}

This work has been carried out with a support of the Department of Mechanical \& Industrial Engineering, Universitas Gadjah Mada, Indonesia under the contract 1560/H1.17/TMI/LK/2016. The authors would like to express sincere gratitude to Dr. Deendarlianto for time spent in serious discussion, helpful suggestion and useful conceptual contribution. We would like to thank also our students Wega, Zeinuri, Aulia, Firdaus, Surya, my laboratory staffs, Waji and Min, their helps in construction work and conducting data management are gratefully acknowledged.

\section{References}

Boelens, O. J. (2012). CFD analysis of the flow around the X-31 aircraft at high angle of attack. Aerospace Science and Technology, 20(1), 38-51. https://doi.org/10.1016/j.ast.2012.03.003

Cai, J., Tsai, H. M., Luo, S., \& Liu, F. (2011). Design of an Optimal Wing-Body Configuration to Delay Onset of Vortex Asymmetry. AIAA Journal, 49(1), 164-171. https://doi.org/10.2514/1.J050595

Calderon, D. E., Wang, Z., \& Gursul, I. (2012). Three-dimensional measurements of vortex breakdown. Experiments in Fluids, 53(May), 293-299. https://doi.org/10.1007/s00348-012-1317-1

Chen, M., Liu, P., Guo, H., \& Qu, Q. (2015). Effect of sideslip on high-angle-of-attack vortex flow over close-coupled canard configuration. Journal of Aircraft, 53(1), 217-230. https://doi.org/10.2514/1.C033305

Cummings, R. M., \& Schutte, A. (2010). An Integrated Computational/Experimental Approach to UCAV Stability \& Control Estimation: Overview of NATO RTO AVT-161. In AIAA Applied Aerodynamics Conference (pp. 1-23). https://doi.org/10.2514/6.2010-4392

Deck, S. Duveau, P., d'Espiney, P., \& Guillen, P. (2002). Development and Application of Spalart-Allmaras One-Equation Turbulence Model to Three-Dimensional Supersonic Complex Configurations. Aerospace Science and Technology, 6, 171-183. https://doi.org/10.1016/S1270-9638(02)01148-3

Erm, L. P., \& Ol, M. V. (2012). An Assessment of the Usefulness of Water Tunnels for Aerodynamic Investigations, (August 2010).

Frohlich, J., \& Terzi, D. von. (2008). Hybrid LES / RANS Methods for the Simulation of Turbulent Flows. Report, 1-52.

Ghoreyshi, M., Cummings, R. M., Ronch, A. Da, \& Badcock, K. J. (2013). Transonic Aerodynamic Load Modeling of X-31 Aircraft Pitching Motions. AIAA Journal, 51(10), 2447-2464. https://doi.org/10.2514/1.J052309

Ghoreyshi, M., Korkis-kanaan, R., Jirásek, A., Cummings, R. M., \& Lofthouse, J. (2016). Simulation validation of static and forced motion flow physics of a canard configured TransCruiser. Aerospace Science and Technology, 48, 158-177. https://doi.org/10.1016/j.ast.2015.11.008

Guoqing, Z., Shuxing, Y., \& Yong, X. (2010). Investigation of Vortex Interaction in Canard-FSW Configurations Based on the Numerical Wind Tunnel Method. Chinese Journal of Aeronautics, 23(3), 312-319. https://doi.org/10.1016/S1000-9361(09)60221-1 
Ito, Y., \& Iwashita, H. (2014). A Study on the Aerodynamic Properties of a Canard-Configuration WISES Highlights : 29th Intl Workshop on Water Waves and Floating Bodies, 29(5), 29-32.

Jee, S., \& Shariff, K. (2014). Detached-eddy simulation based on the v2-f model. In 7 Int Copnf ICCFD (Vol. 46, pp. 84-101). Hawai. https://doi.org/10.1016/j.ijheatfluidflow.2013.12.006

Jin-Jun, W., \& Wang, Z. (2008). Experimental investigations on leading-edge vortex structures for flow over non-slender delta wings. Chinese Physics Letters, 25(7), 2550-2553. https://doi.org/10.1088/0256-307X/25/7/060

Kirkil, G., Constantinescu, G., \& Ettema, R. (2009). Detached Eddy Simulation Investigation of Turbulence at a Circular Pier with Scour Hole. Journal of Hydraulic Engineering, 135(11), 888-901. https://doi.org/10.1061/(ASCE)HY.1943-7900.0000101

Kwak, D., Nelson, R. C., Dame, N., \& Dame, N. (2010). Vortical Flow Control over Delta Wings with Different Sweep Back Angles Using DBD Plasma Actuators. In 5th Flow Control Conference (pp. 1-10). Chicago. https://doi.org/doi:10.2514/6.2010-4837

Lamballais, E., Silvestrini, J., \& Laizet, S. (2008). Direct numerical simulation of a separation bubble on a rounded finite-width leading edge. International Journal of Heat and Fluid Flow, 29(3), 612-625. https://doi.org/10.1016/j.ijheatfluidflow.2008.03.006

Larsson, J., \& Wang, Q. (2014). The prospect of using large eddy and detached eddy simulations in engineering design, and the research required to get there. Philosophical Transactions of the Royal Society A: Mathematical, Physical and Engineering Sciences, 372(2022), 1-15. https://doi.org/10.1098/rsta.2013.0329

Lee, T., \& Su, Y. Y. (2012). Wingtip vortex control via the use of a reverse half-delta wing. Experiments in Fluids, 52(6), 1593-1609. https://doi.org/10.1007/s00348-012-1274-8

Liang, C., \& Papadakis, G. (2007). Large eddy simulation of cross-flow through a staggered tube bundle at subcritical Reynolds number. Journal of Fluids and Structures, 23(8), 1215-1230. https://doi.org/10.1016/j.jfluidstructs.2007.05.004

Liu, C., Liu, C., \& Ma, W. (2015). Rans, detached Eddy simulation and large Eddy simulation of internal Torque converters flows: A comparative study. Engineering Applications of Computational Fluid Mechanics, 9(1), 114-125. https://doi.org/10.1080/19942060.2015.1004814

Lopez, J. M. (1990). Axisymmetric vortex breakdown Part 2. Physical mechanisms. J. Fluid Mech, 221, 553-576.

Mahdi, M. (2015). Prediction of Wing Downwash Using CFD. In 3rd International Workshop on Numerical Modelling in Aerospace Sciences (Vol. 7, pp. 105-111). https://doi.org/10.13111/2066-8201.2015.7.2.10

Meyer, M., Devesa, A., Hickel, S., Hu, X. Y., \& Adams, N. A. (2010). A conservative immersed interface method for Large-Eddy Simulation of incompressible flows. Journal of Computational Physics, 229(18), 6300 6317. https://doi.org/10.1016/j.jcp.2010.04.040

Miller, G. D., \& Williamson, C. H. K. (1997). Turbulent Structures in the Trailing Vortex Wake of a Delta Wing. Experimental Thermal and Fluid Science, 14(96), 2-8.

Mitchell, A. M., \& Delery, J. (2001). Research into vortex breakdown control. Progress in Aerospace Sciences, 37(4), 385-418. https://doi.org/10.1016/S0376-0421(01)00010-0

Mockett, C. (2008). A comprehensive study of detached-eddy simulation. PhD Thesis: TU Berlin.

Morton, S. A, Kholodar, D., Billingsley, T., Forsythe, J. R., Wurtzler, K. E., Squires, K. D., ... Spalart, P. R. (2004). Multidisciplinary applications of detached-eddy simulation to separated flows at high Reynolds numbers (challenge 92). In Users Group Conference, 2004. Proceedings (pp. 103-111). https://doi.org/10.1109/DOD_UGC.2004.28

Muscari, R., \& Mascio, A. Di. (2013). Detached Eddy Simulation of the flow behind an isolated propeller, (May), 218-226.

Nicolleau, F. C. G. A., Cambon, C., Redondo, J. M., Vassilicos, J. C., Reeks, M., \& Nowakowski, A. F. (2012). New approaches in modeling multiphase flows and dispersion in turbulence, fractal methods and synthetic turbulence. ERCOFTAC Series, 18, 9-22. https://doi.org/10.1007/978-94-007-2506-5

Rizzetta, D. P., Visbal, M. R., \& Morgan, P. E. (2008). A high-order compact finite-difference scheme for large-eddy simulation of active flow control. Progress in Aerospace Sciences, 44(6), 397-426. 
https://doi.org/10.1016/j.paerosci.2008.06.003

Sahin, B., Yayla, S., Canpolat, C., \& Akilli, H. (2012). Flow structure over the yawed nonslender diamond wing. Aerospace Science and Technology, 23(1), 108-119. https://doi.org/10.1016/j.ast.2011.06.008

Samimi, S., Davari, A. R., \& Soltani, A. M. R. (2013). Canard-Wing Interactions in Subsonic Flow*. Transactions of Mechanical Engineering, 37(M2), 133-147.

Schütte, A., Rein, M., \& Höhler, G. (2007). Experimental and numerical aspects of simulating unsteady flows around the X-31 configuration. In 3rd Inter Symp on Integrating CFD and Experiments in Aerodynamics 20-21 (pp. 1-16). https://doi.org/10.1243/09544100JAERO387

Sohn, Hwan Myong, \& Chang, W. J. (2010). Effect of a centerbody on the vortex flow of a double-delta wing with leading edge extension. Aerospace Science and Technology, 14(1), 11-18. https://doi.org/10.1016/j.ast.2009.11.004

Spalart, P. R. (2009). Detached-Eddy Simulation. Annual Review of Fluid Mechanics, 41(1), 181-202. https://doi.org/10.1146/annurev.fluid.010908.165130

Squires, K. D. (2004). Detached-eddy simulation : current status and perspectives. In F. R., G. B.J., \& Métais O. (Eds.), Direct and Large-Eddy Simulation V. ERCOFTAC Series, vol 9. Springer, Dordrecht. https://doi.org/https://doi.org/10.1007/978-1-4020-2313-2_49

Squires, K. D. (2010). LES Applications in Aerodynamics. In 2010 Tutorial School on Fluid Dynamics: Topics in Turbulence.

Sun, D., Li, Q., \& Zhang, H. (2013). Detached-eddy simulations on massively separated flows over a 76/40 double-delta wing. Aerospace Science and Technology, 30(1), 33-45. https://doi.org/10.1016/j.ast.2013.07.001

Sutrisno, Deendarlianto, Indarto, Iswahyudi, S., Bramantyo, M, A., \& Setyawan, B. W. (2017). Performances and Stall Delays of Three Dimensional Wind Turbine Blade Plate-Models with Helicopter-Like Propeller Blade Tips. Modern Applied Science, 11(10), 189. https://doi.org/10.5539/mas.v11n10p189

Sutrisno, Deendarlianto, Rochmat, T. A., Indarto, Setyawan B. W., Iswahyudi1, S., ... Djatmiko. (n.d.). The Rolled-up and Tip Vortices Studies in the CFD Model of the 3-D Backward Wind Turbine Blades. To Be Published.

Sutrisno, Deendarlianto, Rochmat, T. A., Setyawan, B. W., \& Iswahyudi, S. (n.d.). The Rolled-up and Tip Vortices Studies in the CFD Model of the 3-D Swept-Backward Wind Turbine Blades. To Be Published. https://doi.org/10.5539/URL

Sutrisno, P., Purnomo, \& Setyawan, B. W. (2016). The performance \& flow visualization studies of three dimensional (3-D) wind turbine blade models. Modern Applied Science, 10(5), 132-144. https://doi.org/10.5539/mas.v10n5p132

Sutrisno, Rochmat, T. A., Setyawan, B. S., Iswahyudi, S., Wiratama, C., \& Widia K. (n.d.). CFD Studies on the Performance and Vortex Breakdown Flow Visualization of Chengdu J-10. To Be Published.

Travin, A., Shur, M., Strelets, M., \& Spalart, P. (1999). Detached-Eddy Simulations Past a Circular Cylinder. Flow Turbulence and Combustion, 63, 293-313. https://doi.org/10.1023/A:1009901401183

\section{Copyrights}

Copyright for this article is retained by the author(s), with first publication rights granted to the journal.

This is an open-access article distributed under the terms and conditions of the Creative Commons Attribution license (http://creativecommons.org/licenses/by/4.0/). 